\title{
GIS-based rockfall hazard zones modeling along the coastal Gulf of Aqaba Region, Egypt
}

\author{
Adel Omran ${ }^{1,2}$ (D) $\cdot$ Kanij Fahmida $^{3} \cdot$ Dietrich Schröder $^{3}$ (D) Mohamed O. Arnous ${ }^{4}$ (D) $\cdot$ Ahmed E. El-Rayes $^{4}$ (D) \\ Volker Hochschild ${ }^{1}$
}

Received: 16 September 2020 / Revised: 16 January 2021 / Accepted: 25 January 2021 / Published online: 13 February 2021

(C) The Author(s) 2021

\begin{abstract}
Rockfall is a natural hazard in mountainous areas not to be underestimated. Mass activities differing in rock volume may cause considerable economic damage. Accomplishing qualitative appraisal of high-potential zones for rockfall is a first step towards implementing mitigation strategies. Nowadays, Geographical Information Systems (GIS) are the state-of-the-art tool for a fast and economic approach of identifying potential hazard zones rather than using conventional mapping with in-situ field data. Primarily, current research focuses on designing and implementing user-friendly tools delineating potential rockfall hazard zonation (RHZ). The constructed model examines triggering factors like slope, aspect, elevation, lithology, structural lineament, rainfall intensity, and seismic activity focal depth of a mountainous coastal region (Gulf of Aqaba, Egypt). The extracted geomorphological parameters were based on a high-resolution TanDEM-X Digital Elevation Model. The enhanced Landsat ETM + 7 was used to generate the lithological and structural lineament parameters, while the rainfall data were collected from NASA project tool. The zonation model was implemented by means of ESRI's ArcGIS Pro ModelBuilder. Google Earth Pro orthophotos compared with the generated rockfall hazard zonation map indicate the potential RHZ with high reliability. The achieved results show that $15 \%$ of the study area qualifies as a high rockfall hazard zone. As the RHZs generated by the model depend on the input data and the selected rating scores and weights, obtaining ground truth is essential to get a trustworthy result. Finally, this study recommends employing the built RHZ model on similar terrains worldwide to support decision-makers involving any sustainable development projects.
\end{abstract}

Keywords Rockfall hazard zonation $\cdot$ ModelBuilder $\cdot$ GIS $\cdot$ Sensitivity analysis $\cdot$ Sinai Peninsula

\section{Introduction}

A hazard like a rockfall may cause damage within the affected area, this includes infrastructure and property as well as all living creatures located there. Rockfall hazards are considered

Communicated by: H. Babaie.

Dietrich Schröder

dietrich.schroeder@hft-stuttgart.de

Adel Omran

adelfouad.omran@suezuniv.edu.eg

Kanij Fahmida

kanijfahmida92@gmail.com

Mohamed O. Arnous

mohamed.arnous@science.suez.edu.eg

Ahmed E. El-Rayes

ahmed_elrais@science.suez.edu.eg as a common type of fast- moving landslide (Hungr et al. 2014) having similar triggering factors. Although rockfalls are a result of a long geological process involving tectonic activities and weathering, the fall may occur suddenly (D'Amato et al. 2015). Not only a high volume of rock, but

Volker Hochschild

volker.hochschild@uni-tuebingen.de

1 Department of Geography, Tübingen University, Rümelinstr 19-23, Tübingen, Germany

2 Department of Science and Mathematical Engineering, Faculty of Petroleum and Mining Engineering, Suez University, Suez, Egypt

3 Department of Geomatics, Faculty of Geomatics, Computer Science and Mathematics, Hochschule für Technik Stuttgart,

Stuttgart, Germany

4 Department of Geology, Faculty of Science, Suez Canal University, Ismailia 41522, Egypt 
also small size rockfalls can create a significant danger because of their possessing a high energy level (Koning and Mansell 2017). Without any extensive monitoring and measuring equipment, a rockfall event is hard to predict for a variety of reasons: these reasons include the timing and dimensions because of the suddenness of the incident, the absence of reliable signals, poor information on the internal structure of the rocky masses, and the tremendous number of triggering components (Lambert and Nicot 2011; Singh al. 2020).

The numerous causes, which include natural growths of population, economic development, and the increasing exploration of tourist attractions, are amplifying the pressure and are boosting the development of remote mountainous areas. In mountainous regions falling rocks constitute a major hazard that can give rise to casualties, damage, and injuries. There are many examples demonstrating the effects of rockfall in mountainous regions. It has been reported in 2010 that about 16 buildings were almost demolished after rockfall in the area surrounding Razaz rock in Cairo's Manshyet Naser - Egypt (Egypt today 2019). In 2008, $16,000 \mathrm{~m}^{3}$ of rock fell down onto the highway between Whistler and Vancouver in Canada (Blais-Stevens et al. 2012). In Turkey, 899 residential areas were exposed to rock fall between the years 1950 and 2005 (Polat and Güney 2013). In India, during the monsoon season (July-September) every year the KalsiChakrata road corridor is exposed to several rock slides and rockfall events. The incidents reported in the national and local newspapers show that this road corridor is frequently blocked by this type of hazard (Sur et al. 2020). Therefore, rockfall hazard zonation (RHZ) represents an important initial step of implementing a risk assessment process that delineates the potential targets and estimates the possible severity of the risk. The main objective of developing the hazard zoning map is to examine the probable impact of such hazards on land-use planning by defining hazard patterns, securing land use, and then applying the appropriate mitigation measures.

Rockfall processes can be described as a rapid deposition of erosion particles from the rock surface, their transportation in free fall (bounce, roll, or slide) and their final sedimentation (Bauer and Neumann 2011). The previous researches have confirmed that slope gradients, earthquakes, heavy precipitation, lithological nature, and active fault pressure are the main triggering factors for rockfall. Topography plays an important role in rockfall incidents across the mountainous areas. Slope, its aspect, and elevation are three topographic parameters triggering rockfall (Duarte and Marquínez 2002; Duran 2016; Çelik and Gülersoy 2017). These studies stated that increasing elevation enhances the possibility of different types of mass movement; in particular, areas with an elevation exceeding $500 \mathrm{~m}$ above sea level in a mountainous area are prone to a higher risk of rockfall events. Statistical analysis by DeGraff and Romesburg (1980) showed a significant correlation between the aspect of a location and geo-hazards like rockfalls.
They classified the risk of the slope aspect according to its direction into high risk (NE \& E), medium risk (SE, S \& $\mathrm{NW}$ ), lower risk (SW \& W), and lowest risk (N, flat surface). This classification is based on the assumption that the surfaces of most arid areas are having higher temperatures and less moisture thus having higher susceptibility towards becoming fractured. There are many variations in rockfall risk based on the range of slope in reviewed literatures such as Arnous (2011), Contino et al. (2017), Saroglou (2019), but mostly, the rockfall risk gradually increases where the slope is greater than $17^{0}$ (DeGraff and Romesburg 1980).

The geological factors comprise lithology and structural lineaments parameters which are considered to be the main parameters influencing rockfall. Therefore, the geological criteria, which includes the types of fracture and the porousness of rock masses, are controlled by the geological stetting of the considered study area. Dorren and Seijmonsbergen (2003) argued that limestone has high rockfall susceptibility, while the lithological units like schists, sandstones, marls, and slats exhibit low to medium susceptibility. Structure lineaments are the surface expression of the hidden architecture of the rock units. These lineament features on the earth surface are caused by fractures within the Earth's Crust, which can be joints, faults, shear zones, or other linear forms. Densely located lineaments decrease the strength of the rock, thus these play an important role in rockfall occurrences (Hussin et al. 2017). Therefore, the profusion of fracture concentration on lithological units has a direct effect on rockfall occurrences. Areas having high lineament density are classified as higher risk zones whereas, the lowest risk zones for rockfall essentially have no or little lineament density.

Different researches (Frayssienes and Hantz 2006; Contino et al. 2017; Saroglou 2019) have proven that rainfall intensity significantly correlated with the incidence of rockfalls. High rainfall intensity develops a hydrostatic pressure on the slope forming material such as colluvium and laterite deposits. The California Department of Transportation (CALTRANS 2014) reported severe rockfalls during the rainstorms because of a washing away of the supporting materials from beneath the larger rock masses in California. The influence of irregular or sudden rainfall is greater than regular rainfall on a rock fall event (Saroglou 2019). Contino et al. (2017) reconstructed a rainstorm triggered powerful rockfall around the Madonie Mountains of Italy. Rockfall can be induced by the loss of supporting material influenced by other agents such as snowmelt and channeled runoff.

Earthquake intensity is considered as an important triggering factor of rockfall (Tanyaș et al. 2019). Moreover, fault zones and structural lineament features in the underlying tectonic plates increase the possibility of seismic induced rockfall by producing fragile and highly fractured rock masses. Stoffel et al. (2019) indicated that the magnitude and epicenter distance of a seismic event are two major influences regarding landslides and rockfall disasters. They also 
mentioned that earthquakes with magnitudes $(M)>7$ could trigger large landslides and rockfalls. Similarly, the depth of the epicenter plays an important role on the influence of seismic events. Generally, the strength of seismic activity diminishes with increasing distance from the earthquake's source (Goff and de Freitas 2016). A rockfall induced by seismic activity occurred in Christchurch, New Zealand, where construction guidelines have been released to avoid any harm by rockfall in the future (Christchurch City Council 2013).

In the last few decades, Geographic Information Systems (GIS) were commonly used to support the prediction, estimation, and monitoring of numerous natural hazards. Through the use of GIS techniques, the created hazard zonation maps are more reliable by combining multi-layered spatial and temporal data. Numerous studies discussed the delineation of geohazard zoning using a weight-rating method, as well as environmental sensitivity evaluations and rockfall analyses of previous rockfall incidents via GIS techniques (Zhao et al. 2017; Saroglou 2019; Depountis et al. 2019).

A hazard information study for the planning and maintenance of highways in Shaanxi province, China, was conducted by Zhao et al. (2017). Terrain gradient, ravening density, geotechnical soil type, and vegetation coverage were the influencing factors considered in the study to achieve information about potential hazards like rockfall, rockslides, slope erosion, and debris flow. Koning and Mansell (2017) prepared rockfall susceptibility maps for the State of New Mexico (U.S.A.) using Kernel function and slope-angle criteria. The Kernel function method has been used to show the point density of the previous rockfall events in the state, while the slope angle has been illustrated as a conventional image of probable future rockfall movement. Although the authors mentioned an insignificant amount of previous rockfall data, the results that have been acquired by both methods matched with the available data.

Three stages of a GIS-based RHZ assessment methodology were introduced by Depountis et al. (2019). They tested their approach in two mountainous regions of Greece by preparing a rockfall inventory map (stage 1 ), a rockfall susceptibility map (stage 2) and a rockfall hazard map (stage 3) considering the intensity and the return period of rockfalls using a rating approach. Another study to determine rockfall susceptibility in Greece engaged a simple weighting approach implemented in a GIS (Saroglou 2019). Depountis et al. (2019) considered as important parameters the slope gradient, lithology, annual rainfall intensity, earthquake intensity, and active fault pressure, all of which trigger the rockfall occurrence.

The overall goal of the current study is towards designing and implementing a user-friendly model for creating a RHZ map of any particular area with input data such as topography, geology, seismic activity, and rainfall. The model is mainly designed for qualitative analysis of the areas where a possible rockfall hazard can occur, and in turn, threaten the surrounding people, livelihood, and infrastructure, as well as the environment. For testing, a study area (western coastal region of the Gulf of Aqaba, Egypt) has been chosen regarding its topography, climate, and the importance of its land use as a tourist attraction site. The investigated area has been affected by many rockfall points especially along the main highways (Fig. 1). For deciding the best combination of weights of the considered parameters, a sensitivity analysis has been performed. Last, but not least, this study serves as a qualitative assessment for rockfall occurrence and provides a methodology for a RHZ map that could be expanded in use across comparable regions in Egypt and elsewhere.

\section{Site description}

The selected study area is a part of the western coast of the Gulf of Aqaba, Egypt. The area covers about $8,215 \mathrm{~km}^{2}$ and contains the main tourism cities of Dahab, Saint Catherine, and Nuweiba. It is bounded by longitudes $33^{\circ} 55^{\prime} \mathrm{E}$ and $34^{\circ} 45^{\prime} \mathrm{E}$ and latitudes $27^{\circ} 55^{\prime} \mathrm{N}$ and $29^{\circ} 05^{\prime} \mathrm{N}$. The investigated area can be accessed from the south via the Sharm El Sheikh - Dahab highway, and from the north through Nuweiba - Dahab highway, the Sharm El Sheikh - Nuweiba highway runs along a tributary of Wadi Dahab, while the Nuweiba - Dahab highway runs along the main stream of Wadi Dahab (Fig. 2). The climate of the area has been classified as a typical hyper-arid desert (Lin 1999), where it receives an average annual rainfall ranging from about $10 \mathrm{~mm}$ near the coast and increasing toward the inner highlands to about $50 \mathrm{~mm}$ (Omran 2013). Although it receives such little rainfall,

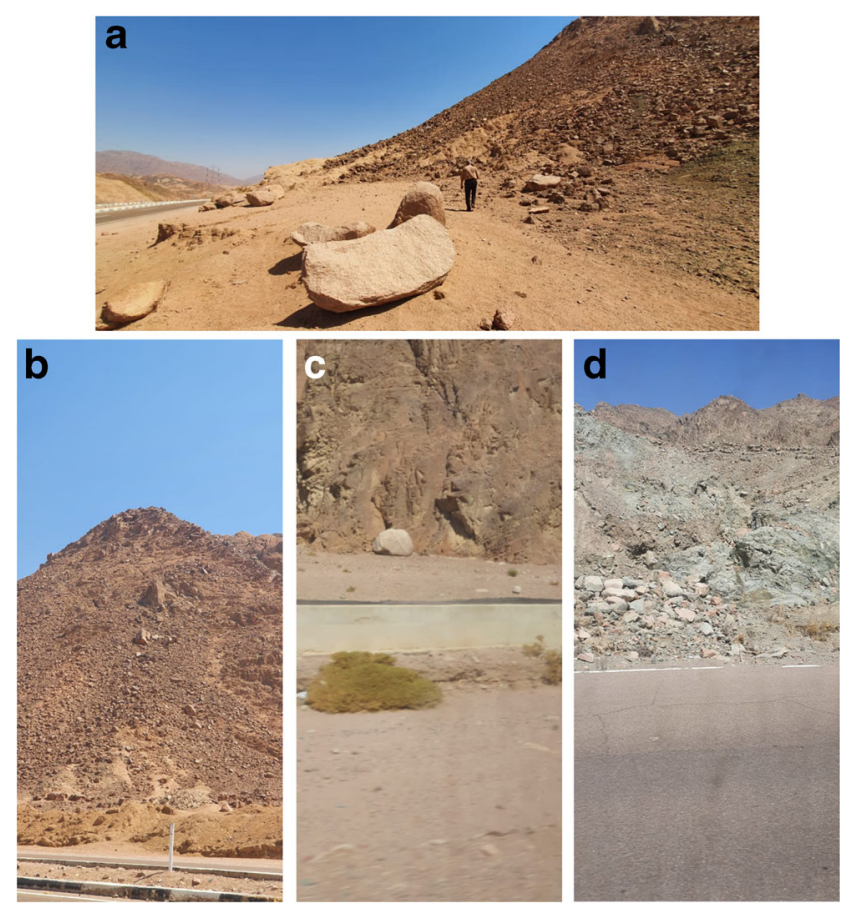

Fig. 1 a-d Field Photos showing the observed rockfall points at different location in the study area 
the investigated area has frequently witnessed severe flash flooding that have been primarily initiated from within the nearby mountainous areas (Prama et al. 2020). Most of the precipitation events have occurred during the periods between September and December. During these months, the area experiences short, but very intensive, rainfalls which bring the area close to overflow (Omran 2013). These events can be considered as alarming threats to the settlements and lives that are located at the downstream openings of the Sinai Mountain valleys (Crane 2015). Maximum and minimum temperatures are approximately $45^{\circ} \mathrm{C}$ and $0{ }^{\circ} \mathrm{C}$ respectively during the last 10 years (POWER Data Access Viewer 2019).

The demography has been studied in the South Sinai Environmental Action Plan based upon a number of assumptions concerning the rate of increase regarding operating hotels, the indirect tourism employment multipliers, and the settlement of families of tourism workers. In 1960 the Census of Egypt recorded only 4,355 inhabitants in South Sinai, almost all of whom were indigenous Bedouin. By 2017, the number of inhabitants had increased to 300,000 (SSRDP 2006). The governmental agencies are concerned with improving infrastructure and service delivery to rural settlements. These settlements are populated by Bedouin and are very dispersed within the study area (Fig. 2).

The lithology of the study area is mainly divided into two main rock units, namely the Precambrian and the Phanerozoic (Said 1960, 1970; Ghorab 1961; Nassif 1997). The Precambrian rocks include metamorphic and magmatic rock affinities, which constitute about $57 \%$ of the rocks covering the study area. The magmatic rocks have a relatively younger age than the metamorphosed rocks and are differentiated into volcanic and plutonic varieties. The metamorphic rocks form the southernmost extension of a metamorphic belt that is exposed along the western side of the Gulf of Aqaba. The Phanerozoic rocks cover a vast portion of the study area and are classified into numerous stratigraphic formations. Sandstone rocks cover about $551.3 \mathrm{~km}^{2}$ being mainly distributed at the northern part of the study area. Limestones constitute about $9 \%$ of the rocks located in the investigated area and are distinguished by the Wata Formation and the Thebes Formation. These formations are cropped out at the northern part of the study area (Fig. 3). The wadi alluvial deposits are vastly distributed along the valley bottoms of the study area with about $12 \%$ coverage. These Quaternary deposits consist of loose sediments mainly of sands, slits, and gravels (Fig. 3).

Lineaments are used to describe the linear topographical characteristics of regional extent that are believed to reflect the geological structures. Although lineaments are features of surface topography, they also reflect the subsurface structures. Furthermore, the fault zones increase the risk for rockfall potentiality by producing steep slopes and weakened, highly fractured rock masses (Saroglou 2019). The investigated area is a part of a shear belt observed along the western side of the Gulf of Aqaba. This shear zone is made of successive NNE-SSW trending pull apart basins. It is a part of displacement depicted along the Dead Sea Rift (Garfunkel 1981; Eyal et al. 1981). The lineament features are dominated by faults having a NE-SW direction that is parallel to the main direction of dikes intruding into the Precambrian basement rocks. A second set of faults have a NNE-SSW trend, whereas a third set assumes a NW-SE trend and consists of short faults (Arnous and Green 2011, El Rayes et al. 2020). Moreover, a set of fractures comprising the E-W trending strike slip faults constitutes the subordinate abundance relative to the other sets (Fig. 3). These sets of faults cut up the basement rocks into NNE-SSW elongated blocks tilted towards the Gulf of Aqaba.

The seismicity reflects the tectonic activity of surface structural elements of the investigation area. The study area is located along the Gulf of Aqaba which it is situated along the southern part of the Dead Sea Transform Fault that forms the boundary between the African and the Arabian plate. This area is subjected to many high seismic events. For instance, on November 22, 1995, a massive seismic tremor estimated to be over 7.0 degrees hits the southern parts of the Dead Sea Rift Line in the Gulf of Aqaba close to the port of Nuweiba, to the north of the study area (Omar et al. 2020). The extensive seismicity triggered rockfalls which may have been a result of local amplification of seismic shaking (Harp and Jibson 1996). Therefore, the effect of earthquakes should be taken into account on the susceptibility for rockfall hazard.

\section{Data and methods}

\section{Data used}

The primary information about the data used for implementing the RHZ model is listed in Table 1. All these necessary data have been collected from secondary sources. The main topographic data such as elevation, slope, and aspect have been extracted from a DEM (TanDEM-X) provided by Deutsches Zentrum für Luft- und Raumfahrt (DLR). The standard DEM offered has a ground resolution of $0.4 \operatorname{arcsec}$ which equals about 12 meters at the equator (Fig. 3). Lineament data has been extracted from the enhanced Landsat $7 \mathrm{ETM}+$ panchromatic band with spatial resolution of 15-meters, in addition, structural lineament data from Arnous and Green (2011) was used. The seismicity activities and their distribution throughout the study area during the period 1900-2005 has been obtained from the National Earthquake Information Center, the International Seismological Centre, and the Egyptian National Seismic Network (Fig. 4). 


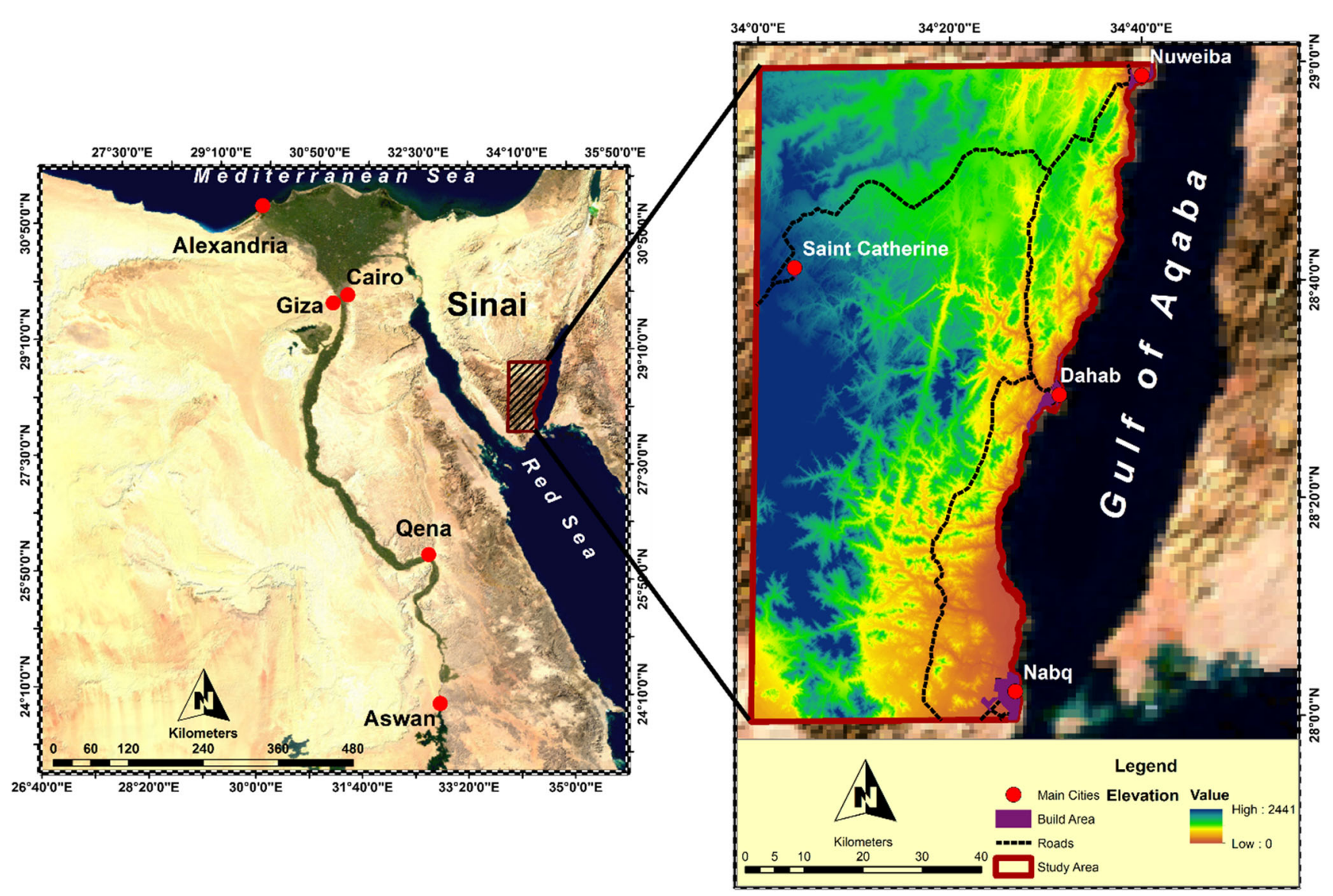

Fig. 2 Location map showing the topographic pattern, main roads, and the key cities of the study area

The rainfall data were extracted using the 'power regional data access tool' of the 'POWER Data Access Viewer' POWER is a NASA project that was initiated in 2003. The source for meteorological data of POWER is the latest atmospheric reanalysis of the modern satellite era produced by NASA's Global Modeling and Assimilation Office (Gelaro et al. 2017). All the input data (raster and vector) were converted to the same projection system WGS_1984_UTM_Zone_36N for inserting into the model. Orthophotos from Google Earth Pro were used to create a land use map for the study area and for preliminary validation of the final results. For designing and implementing the model, the ESRI ArcGIS Pro ModelBuilder was used as the visual programming tool.

\section{Methodology}

The RHZ model implementation is based mainly on the geoprocessing tools of the Spatial Analyst toolbox of ArcGIS Pro. To use these tools, a homogenization of the input data is necessary, related to the spatial reference system, clipping to the area of interest, and a data type conversion to raster data. The raster layers are reclassified based on the expert knowledge of the user who will decide which of the scoring values shall be applied and the weights of the parameters. The sum of the weighted layers is finally transformed into a RHZ map (Fig. 5). Default scoring values for each parameter have been selected by reviewing related researches as reference values. The weighting values have been determined after performing a sensitivity analysis. The achieved RHZ model has been verified qualitatively using land use data extracted from Google Earth Pro.

\section{Homogenization of input data}

This step is highly dependent on the format of the available input data. As the model is based on raster data processing, all the input data must be converted into raster layers with the same resolution. For the study area used, the elevation data was provided as a DEM, so the topographical parameter slope and aspect have been extracted from this raster layer (Fig. 6). Based on the point locations, the rainfall data has been interpolated using the Inverse Distance Weighting method.

Lineaments are usually represented in GIS as polyline vector data. To be used in the rockfall model, the polylines are converted to raster by calculating their densities. The lithological units, given as vector polygons, have been rasterized based on a classification of the units regarding their susceptibility to rockfall occurrences. Seismic activity data is presented as point 

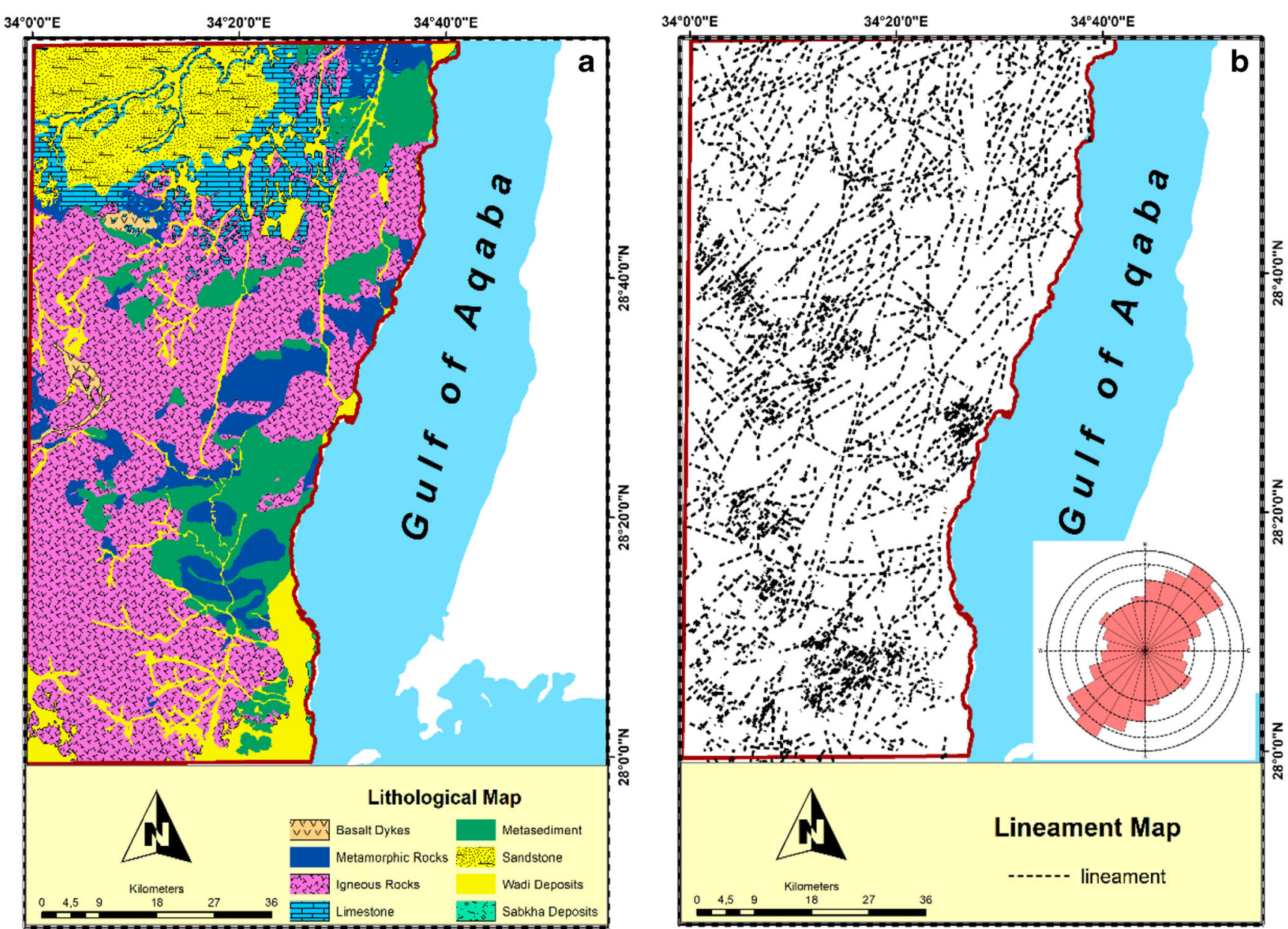

Fig. 3 a The lithological map of study area showing the spatial distribution of the involved rock units (EGSMA 1994). b The structural lineaments map of the study area (modified after Arnous and Green 2011)

vector data. Two different raster layers, i.e. depth and magnitude of seismic activity, were created using interpolation. Beside the format and type conversion, the homogenization also includes the masking of the study area, as well as the reprojection to the UTM projection and the conversion to the WGS84 geodetic datum, if necessary. Figure 6 summarizes the homogenization steps for the input data of the study area.

\section{Reclassification of raster layers using scoring values}

In this step, the homogenized raster layers from the first step are reclassified regarding their susceptibility to rockfall hazards. The resulting raster values associated with each layer parameter were interpreted as score values related to the RFH an overlay operation for all layers was used to get the sum of scores for each pixel which was then used as a relative measure of the potential for RFH. Each parameter is reclassified in not more than five score levels and normalized to a scale ranging from 0 to 100 according to Eq. 1. The normalized score values for each parameter were calculated using a simple statistical approach (DeGraff and Romesburg 1980; Arnous 2011; Prama et al. 2020), see Table 2.

$\mathrm{X}_{\mathrm{j}}=\left(\mathrm{R}_{\mathrm{j}}-\mathrm{R}_{\text {min }}\right) /\left(\mathrm{R}_{\max }-\mathrm{R}_{\min }\right) \times 100$
Table 1 Input data for implementing the RHZ model

\begin{tabular}{lllll}
\hline No. & Data & Data type & Duration (year) & Data source \\
\hline 1 & $\begin{array}{l}\text { Digital Elevation } \\
\text { Model (DEM) }\end{array}$ & Raster & 2018 & TanDEM-X-12 m \\
2 & Lithological Units & vector & - & Arnous and Green 2011 \\
3 & Structure lineaments & vector & - & Arnous and Green 2011 \\
4 & Seismic activity & vector & $1900-2005$ & National Earthquake Information Centre \\
5 & Annual rainfall & CSV & $1984-2013$ & POWER Data Access Viewer 2019 \\
\hline
\end{tabular}




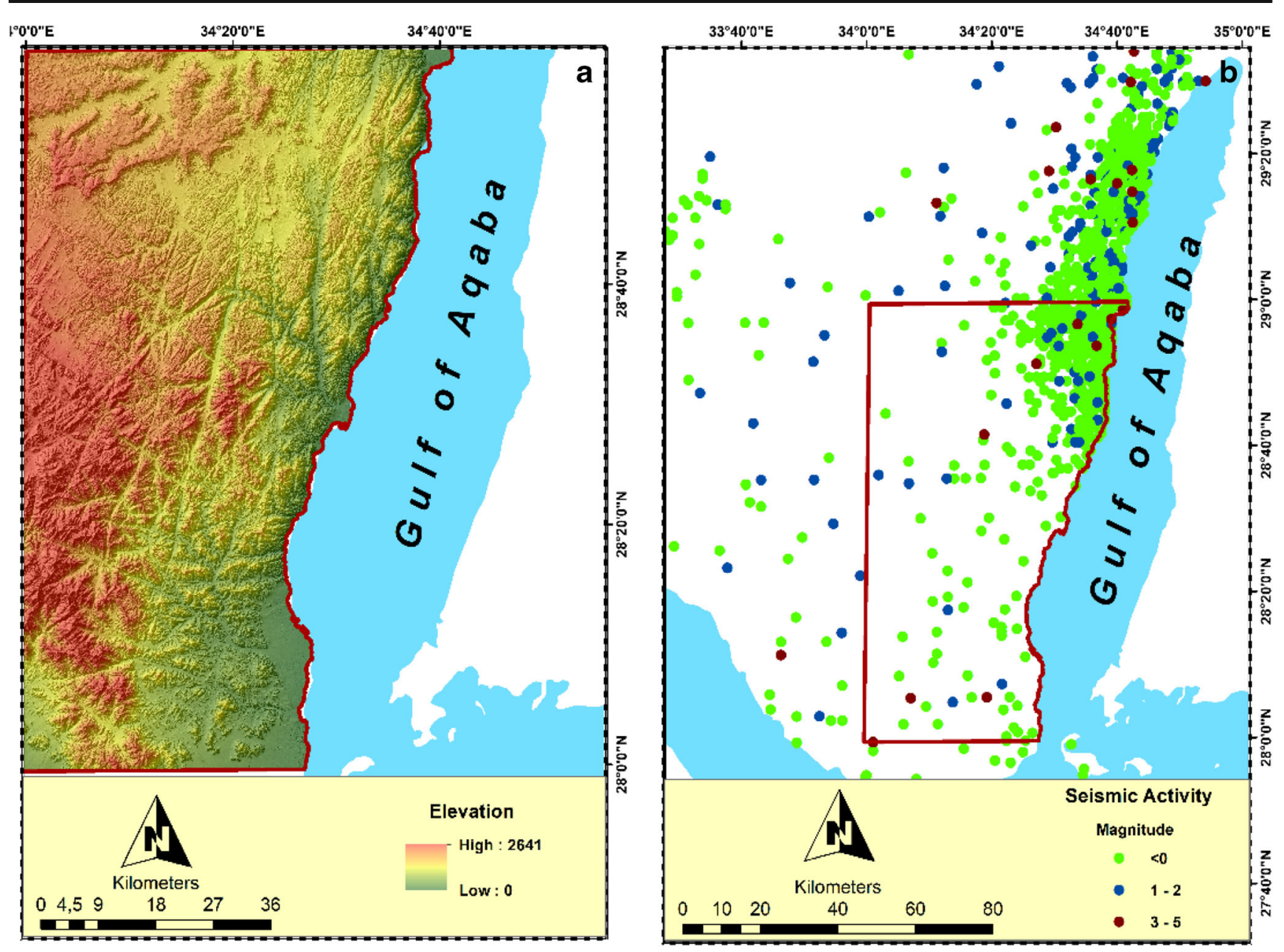

Fig. 4 a Digital Elevation Model (TanDEM-X) of the study area. b Spatial distribution of earthquakes magnitudes of the study area

Where:

$\mathrm{X}_{\mathrm{j}}=$ normalized score $\mathrm{R}_{\mathrm{j}}=$ raw score.

$\mathrm{R}_{\min }=$ minimum score $\mathrm{R}_{\max }=$ maximum score.

\section{Generating the final weighted map and the RHZ map}

In this step, all thematic layers were arranged in hierarchical order of importance for rockfall hazard and a weighting number was assigned to each layer. This weighting number can be set by the user of the model, default values are provided. The normalized scored maps from the previous step are multiplied by the corresponding weights to yield the weighted raster layer for each parameter.

The weight value of each layer can be changed according to the condition of each study area. For instance, Çelik and Gülersoy (2017) have listed weighted values for different parameters for modeling of rockfall hazards for the area of Kilis in Turkey, whereas Arnous (2011) have used different values for a landslide hazard modeling at Wadi Watir in South Sinai. Therefore, for the study area of this research, a statistical analysis to select the appropriate weighting values has been used.

Sensitivity analysis is a common method used in decision making of various fields such as economics, physics, social sciences, and the medical field. It is a method to reduce the uncertainty of prediction by high impact parameters. The aim of this analysis is to get an overview of the effectiveness of different weights assigned to different parameters and deciding the final weighting values of each parameter. Among all the different approaches for sensitivity analysis the 'one-factorat-a-time' method (OAT), is applied in this research. Here, the input parameters are changed one by one, keeping the others fixed in a baseline and monitoring changes in the final ou2tcome (Al-Mashreki et al. 2011).

Finally, a summation of all weighted layers affecting rockfall was carried out and the cumulative score was regrouped into three classes. An overlay operation was used to evaluate the intersected regions by the sum of the weighted layers, so that each region can be characterized by a score value indicating its potential for rockfall probability. 


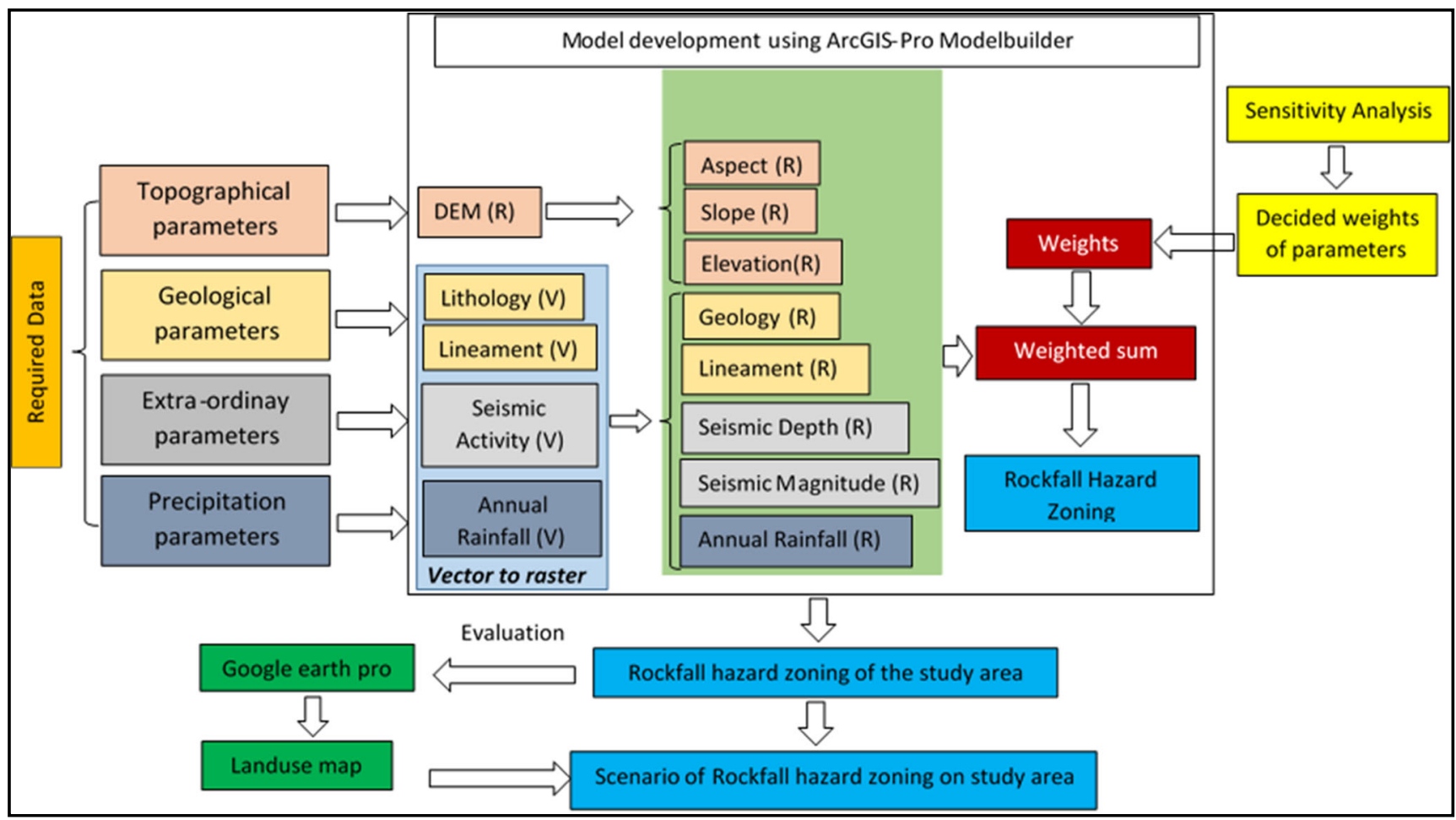

Fig. 5 General workflow of the RHZ model

\section{Results and discussion}

A rockfall potentiality mapping model is used in this study to investigate the threat to people, infrastructure, and the environment. Furthermore, the evaluation of the existing conditions which could pose a potential threat to people, land use activities, and the sustainable development of the area is also a part of the investigation. After the initial homogenization step, all raster layers have been reclassified so that the scoring values reflect the susceptibility to rockfall (Fig. 7). The scores for the lithological units were based on values used by other authors, such as Arnous (2011) and Saroglou (2019). The values have been selected with regard to an excess abundance of rock blocks based on the usual rock mass structural conditions and behavior encountered in these categories as given in Table 2. Dorren and Seijmonsbergen (2003) stated that limestone has a high susceptibility to rockfall while sandstone and marls have low susceptibility (risk). Arnous (2011) stated that igneous rock has high potentiality for landslide hazards. Therefore, the lithological units have been classified into five classes where basement rocks and limestone are given the highest score of 5 and 4, respectively, while friable wadi deposits and sandstone were scored low with 2 and 1 , respectively (Fig. 7a).

Structural analysis of lineaments provides important parameters for delineation areas prone to rockfall. Brideau et al. (2005) observed that the block size and shape vary as a function of the distance from a fault. The extent of the damage zones that they observed is up to $10 \mathrm{~m}$. The damage distance zone has been used in the density tool for the lineament layer as a radius buffer. The scored values for structure lineament have been classified into five equal classes as in Arnous (2011) (Table 2). The areas with high lineament density are scored with the high value of 5. These areas are mainly associated with basement rock units which are highly dissected with lineament features (Fig. 7b).

Rockfall are among the most common earthquake-induced secondary effects. The magnitude of seismic activity is the most common measure of an earthquake's size. It is a measure of the strength of an earthquake and is usually measured using the Richter magnitude scale based on the logarithm of the amplitude of the earthquake wave. At the study area, the higher magnitude data is rated at 5 while the lower value is rated at greater than 0.5 regarding the collected data from the National Earthquake Information Center (https://earthquake. usgs.gov/earthquakes/search) and the International Seismological Centre (http://www.isc.ac.uk), as well as the Egyptian National Seismic Network (ENSN).

The strength of the earthquake shaking increases as the depth of the epicenter decreases (Goff and de Freitas 2016). Saroglou (2019) classified the strength of the seismic activity and its effect on the rockfall hazard into three classes. Thus, in the model the two seismic parameters have been reclassified into three main classes. The high score value will be assigned to both the lower depth of seismic activity and concurrently it will be given to the higher magnitude of earthquake. The high 


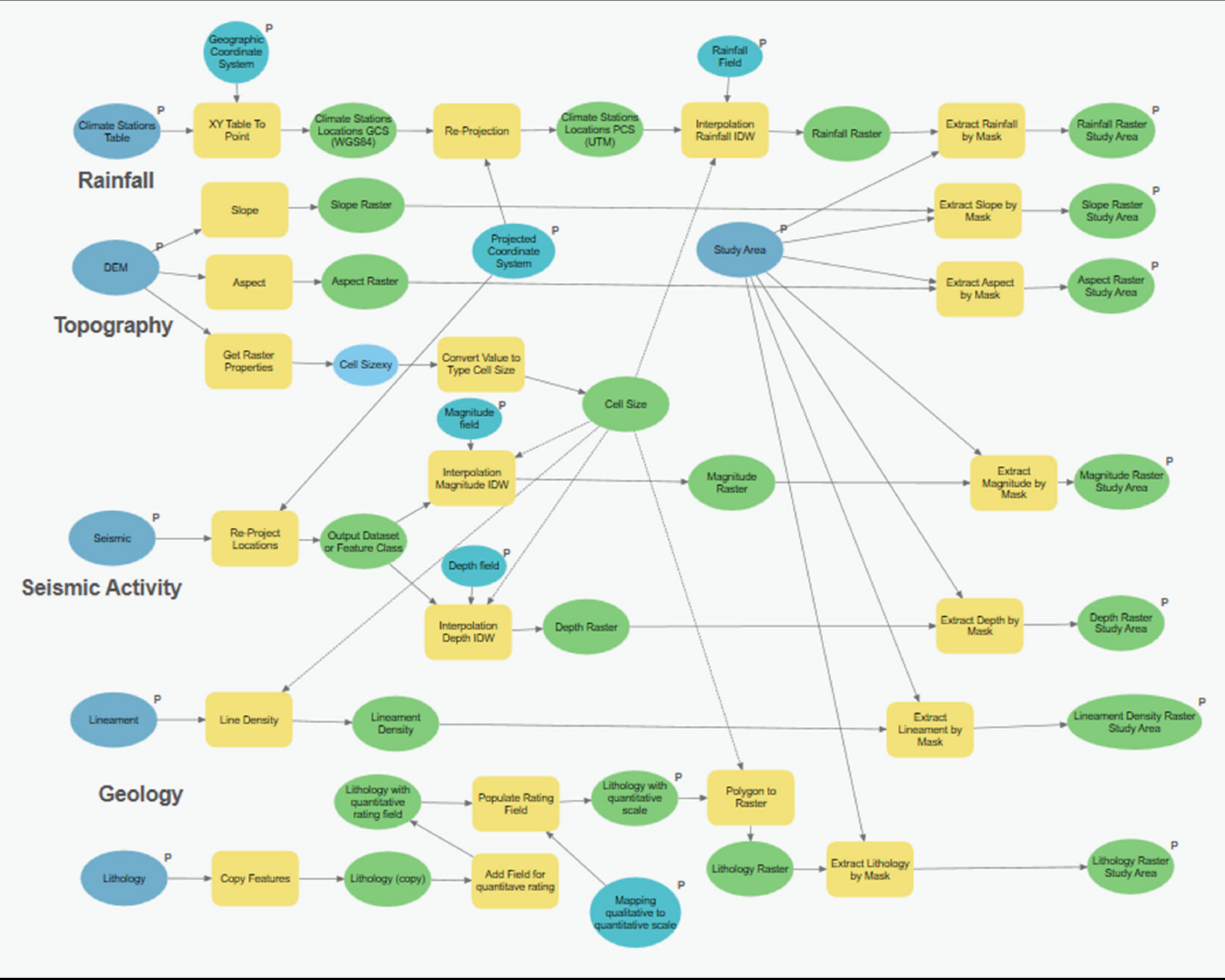

Fig. 6 Homogenization of the input data

class was scored to value 5 which is indicative of both high magnitude of seismic activity and low depth of earthquake epicenter, respectively (Figs. 7c- 6d).

The topographical parameters have been extracted from TanDEM-X data. Slope-angle is one of the most important factors of slope instabilities causing rockfall to occur on steep slopes. The adopted cut-off value for slope gradient, above which rock slope instability may occur, is $45^{\circ}$ according to Meisina et al. (2001). Saroglou (2019) stated that areas with a slope greater than $27^{0}$ degrees are more susceptible for rockfall, while Arnous (2011) has classified the slope regarding landslides hazards into five classes. He pointed out that the highest landslide densities occur between about $20-35^{\circ}$. Therefore, the slope parameter has been reclassified and scored into five classes according to Arnous (2011) in Table 2, where the highest class has been assigned to slopes of more than $45^{\circ}$ (Fig. 7f).

The aspect, i.e. the direction the slope faces, is relative to some other factors that may affect rockfall occurrences such as wind direction and direction of seismic waves (Dai et al. 2011). The prevailing wind direction is northeast at the western, southern, and eastern parts of the study area (Omran 2013). Most of the wadis in the study area are directed eastward and finally flow into the Gulf of Aqaba. The density of landslides is smallest for south, southwest, and west facing slopes (Omar et al. 2004) and the study area is more affected by landslides at the northeast and east directions (Arnous 2011). Therefore, the aspect parameter was reclassified into five classes with highest score for northeast and east directions while the lowest scored was assigned to the north direction (Fig. 7e).

Rock failures are widespread at any elevation, from mountain areas to coastal cliffs, affecting the evolution and stability of different landscapes. Since the heights and topography parameter vary considerably, rockfall behavior becomes quite erratic and difficult to predict (Sazid 2019). But elevation can be related indirectly to the climate effect on the occurrence of rockfall. At high elevations, climatic factors are more 
Table 2 Scoring and classification of all parameters used in the RHZ model

\begin{tabular}{|c|c|c|c|c|c|}
\hline Factor & Parameter & Attribute & Raw Score $(\mathrm{Rj})$ & Normalized Score $(\mathrm{Xj})$ & Relative value \\
\hline \multirow[t]{14}{*}{ Topography } & \multirow{5}{*}{$\begin{array}{l}\text { Slope } \\
\text { (Arnous 2011) }\end{array}$} & $<15$ & 1 & 0 & Very low \\
\hline & & $15-25$ & 2 & 25 & Low \\
\hline & & $25-35$ & 3 & 50 & Moderate \\
\hline & & $35-45$ & 4 & 75 & High \\
\hline & & $>45$ & 5 & 100 & Very high \\
\hline & \multirow{4}{*}{$\begin{array}{l}\text { Aspect } \\
\text { (Arnous 2011) }\end{array}$} & $\mathrm{N}$, flat & 1 & 0 & Very low \\
\hline & & SW \& W & 2 & 25 & Low \\
\hline & & SE, S \& NW & 3 & 50 & Moderate \\
\hline & & $\mathrm{NE} \& \mathrm{E}$ & 5 & 100 & Very high \\
\hline & \multirow{5}{*}{$\begin{array}{l}\text { Elevation } \\
\text { (Arnous 2011) }\end{array}$} & $<500$ & 1 & 0 & Very low \\
\hline & & $500-1000$ & 2 & 25 & Low \\
\hline & & $1000-1500$ & 3 & 50 & Moderate \\
\hline & & $1500-2000$ & 4 & 75 & High \\
\hline & & $>2000$ & 5 & 100 & Very high \\
\hline \multirow[t]{10}{*}{ Geology } & \multirow{5}{*}{$\begin{array}{l}\text { Lithology } \\
\text { (Arnous } 2011 \\
\text { Saroglou 2019) }\end{array}$} & Silt and clay (Sabkha deposits) & 1 & 0 & Very low \\
\hline & & Sediment (Wadi deposits) and metasediment & 2 & 25 & Low \\
\hline & & Sandstone & 3 & 50 & Moderate \\
\hline & & Igneous rock (Basalt), Limestone & 4 & 75 & High \\
\hline & & $\begin{array}{l}\text { Metamorphic rocks (Gniess, marbel, } \\
\text { metadiorite, metavolcanic and } \\
\text { metagabbro); Igneous rock } \\
\text { (Granites, Gabbro, Diorite) }\end{array}$ & 5 & 100 & Very high \\
\hline & \multirow[t]{5}{*}{ Lineament density } & $<0.00077$ & 1 & 0 & Very low \\
\hline & & $0.00077-0.0015$ & 2 & 25 & Low \\
\hline & & $0.0015-0.0023$ & 3 & 50 & Moderate \\
\hline & & $0.0023-0.0031$ & 4 & 75 & High \\
\hline & & $>0.0031$ & 5 & 100 & Very high \\
\hline \multirow[t]{5}{*}{ Climate } & \multirow[t]{5}{*}{ Rainfall intensity } & $<0.13$ & 1 & 0 & Very low \\
\hline & & $0.13-0.15$ & 2 & 25 & Low \\
\hline & & $0.15-0.17$ & 3 & 50 & Moderate \\
\hline & & $0.17-0.19$ & 4 & 75 & High \\
\hline & & $0.19-0.22$ & 5 & 100 & Very high \\
\hline \multirow[t]{6}{*}{ Seismic activity } & \multirow{3}{*}{$\begin{array}{l}\text { Seismic Magnitude } \\
\text { (Saroglou 2019) }\end{array}$} & $<0$ & 1 & 0 & Very low \\
\hline & & $1-3$ & 3 & 50 & Moderate \\
\hline & & $3-5$ & 5 & 100 & Very high \\
\hline & \multirow{3}{*}{$\begin{array}{l}\text { Seismic Depth } \\
\text { (Saroglou 2019) }\end{array}$} & $0-20$ & 5 & 100 & Vey high \\
\hline & & $20-30$ & 3 & 50 & Moderate \\
\hline & & $30-40$ & 1 & 0 & Very low \\
\hline
\end{tabular}

critical for rockfall stability, since they control weathering processes (mainly through temperature regime and precipitation activity). The higher elevation areas of the study area are characterized by high differences in daily temperature especially at the Saint Catherine area (more than $2000 \mathrm{~m}$ ). Arnous (2011) has classified the topography at the northern part of the study area into 5 classes corresponding to landslide occurrence. Therefore, the elevation parameter has been reclassified regarding rockfall hazard susceptibility into 5 classes (Fig. $7 \mathrm{~g}$ ). The areas with more than $2000 \mathrm{~m}$ a.s.l. has been scored the highest value while the areas of less than or equal to $500 \mathrm{~m}$ a.s.l. have been scored with the lowest value.

Rainfall itself does not trigger rockfall directly; it is the impact of rainfall on the destabilization of the soil that abets rockfall. Infiltrating rainfall can significantly increase the soil pore pressure and thus induce slope movement (Hoek and Bray 1981; D'Amato et al. 2015). It has been discussed by many studies such as (Contino et al. 2017; Saroglou 2019) that rainfall intensity correlates with the occurrence of rockfall. A simple rating was proposed by Saroglou (2019) determining 

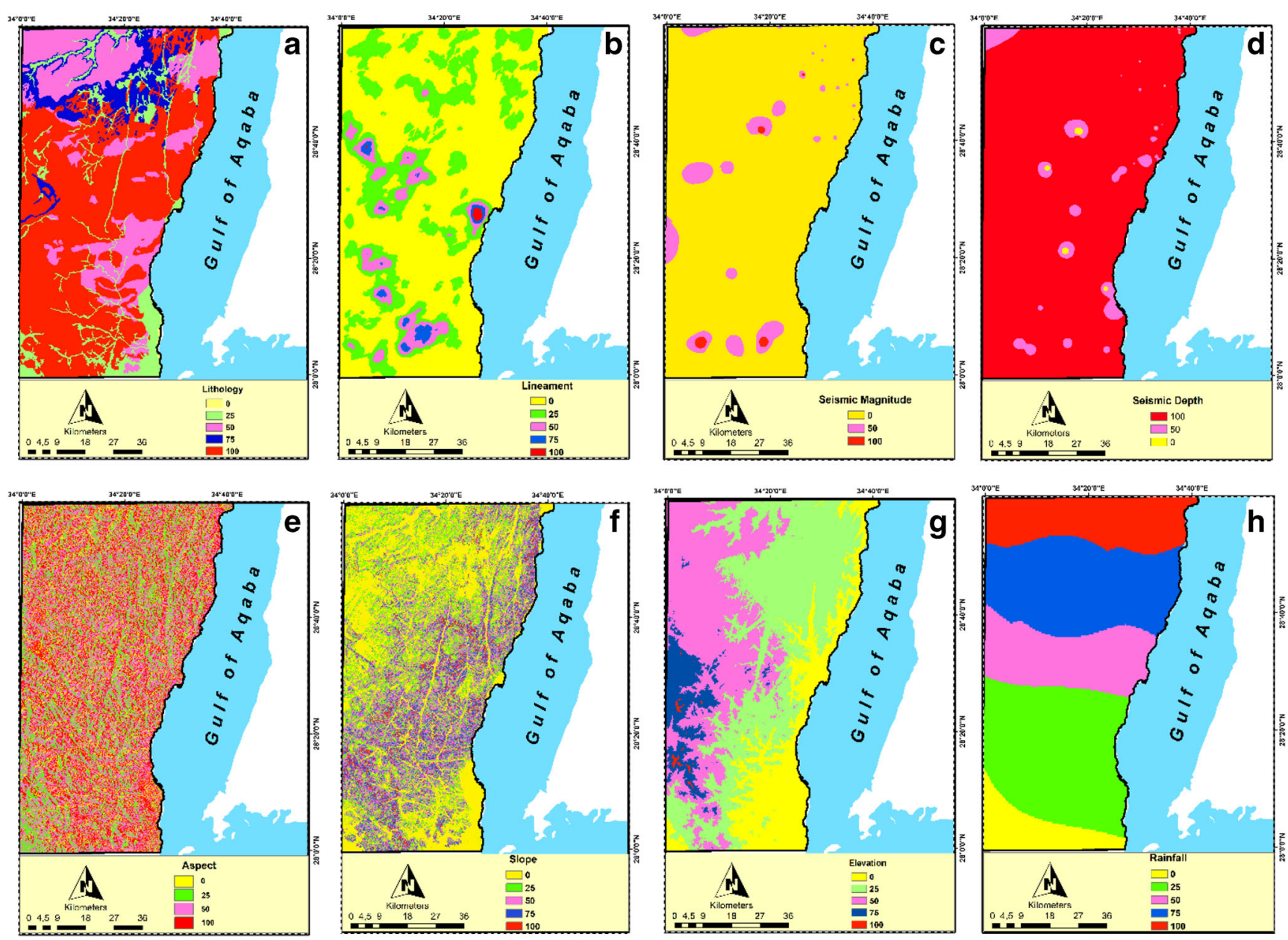

Fig. 7 a-h The result of the model for the raster generation step for all parameters affecting on RHZ

that rockfall susceptibility increases with annual rainfall intensity. For the study area, the total annual rainfall data for the thirty-year period between 1984 and 2014 has been considered. The rainfall amount ranged between 300 and $1700 \mathrm{~mm} /$ year. These amounts reflect the low intensity of the rainfall mirroring the arid climate of the study area. However, the intensity of daily rainfall up to $45 \mathrm{~mm} /$ day may have a strong impact on the instability of the rock mass. The precipitation has been classified into five equal classes. (Fig. 7h).

The weights of each parameter have been selected according to the sensitivity analysis. Based on them, the final map of RHZ has been created. Saltelli et al. (2000) states that with a sensitivity analysis the variation of the output of a model can be apportioned with respect to the quantity and quality of the model input. The analysis has been performed to characterize the influencing level of the different factors on the RHZ in the study area. It serves as assistance in reducing the uncertainty of prediction by high impact parameters (Frey et al. 2004). This analysis helps with operating the model by using appropriate weighted input data and the stability of its outputs by illustrating the effect of making slight changes to specific input parameters.
There are many approaches for a sensitivity analysis varying from differential to Monte Carlo analysis, from measures of importance to sensitivity indices, from regression or correlation methods to variance-based techniques (Archer et al. 1997; Crosetto et al. 2000; Saltelli et al. 2000) down to simple screening approaches. In this study, the one-factor-at-a-time (OAT) method has been used, which alters one model parameter in a model run and analyzes the variation in the resulting model output. This method has been used in different GIS model applications (Al-Mashreki et al. 2011; Mair et al. 2012) despite the well-known disadvantage of the OAT method not considering parameter interdependencies.

The sensitivity analysis is done for all eight parameters considered in the model. For each parameter, four different weighting schemes were adopted, and the other parameters were given equal weightings. In every scheme, the total weight of all parameters is fixed to 100 , therefore the weighting is presented as a percentage share. For each parameter, the weighting schemes are $10 \%, 30 \%, 50 \%$, and $70 \%$ of the total weightings of all parameters.

Results of each model run are represented in maps for interpretation and further investigation. For each input weighted 

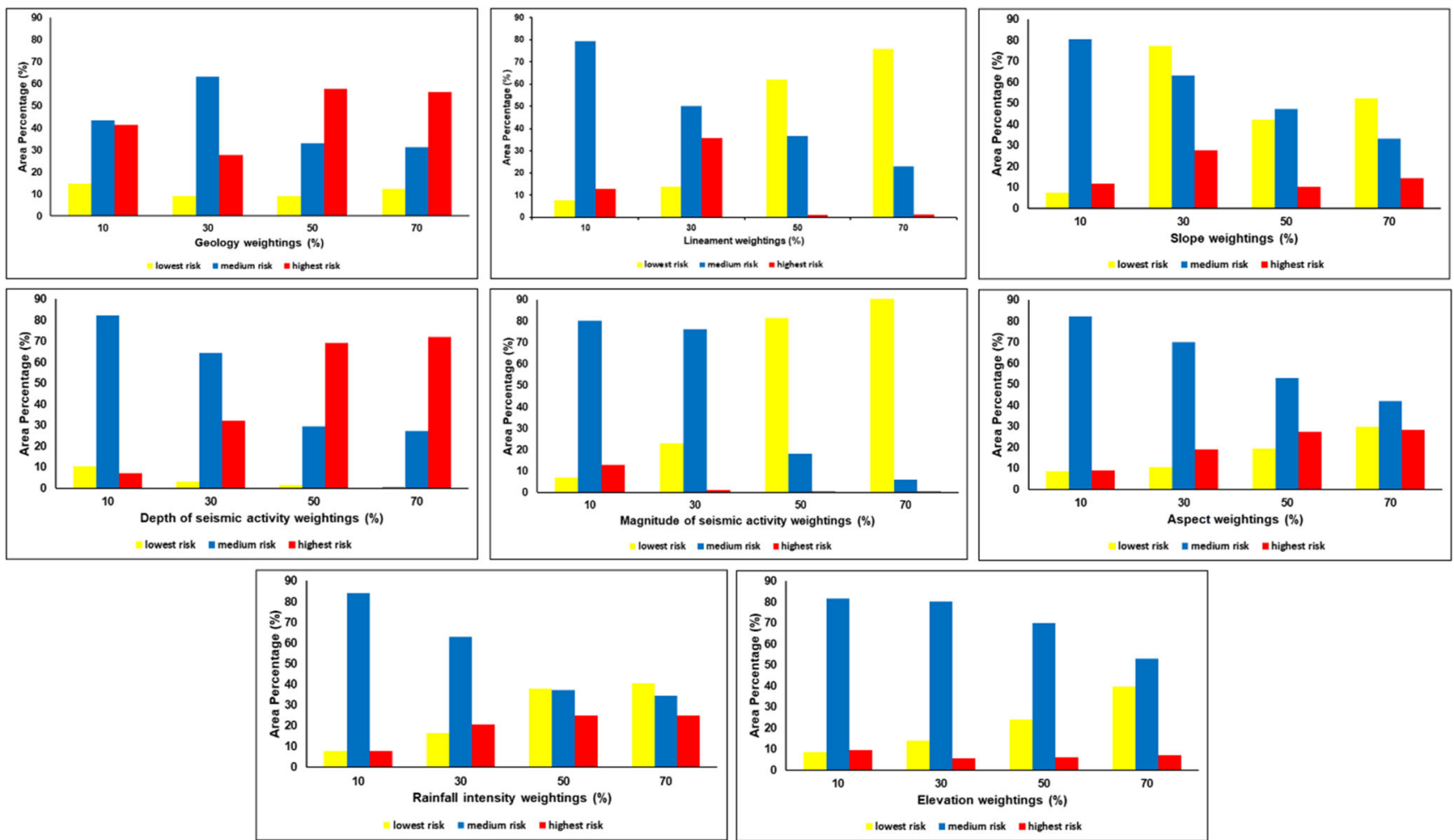

Fig. 8 The results of sensitivity analysis for all parameters affecting rockfall

value, the study area is classified in three different rockfall hazard zones (lowest risk, medium risk, and highest risk). Depending on the sensitivity analysis, the weights of each factor are assigned in the range of 1 to 5 , where 1 and 5 are minimum and maximum sensitivity, respectively. These weight values are selected based upon: (1) dramatic or gradual rise or fall of the highest risk area percentage, (2) calculating the shifts in the highest risk area percentage when the weight is changing.

Visual assessment of the delineated RHZ and their percentage area was used to interpret the output of the sensitivity analysis. Figure 7 shows the sensitivity analysis of all parameters based on the different weighting values representing rockfall hazard. It revealed that the lithological parameter is highly sensitive to the potential rockfall event in the study area. There is a dramatic change of the high risk area from $42-28 \%$ when the weight of geology increases by $10-30 \%$. It indicates that other factors dominated when the geology factor was weighted at $10 \%$. It was observed that there is a sudden increase in potential high-risk areas in maps from $27-57 \%$ when the weighting increases to $30 \%$ and $50 \%$, respectively. In the fourth case of weighting ( $70 \%)$ only a minor decrease $(2 \%)$ in the highest risk area can be observed.

For the sensitivity analysis of the lineament parameters, there is a gradual declination of medium risk area when weighting criteria changes. However, there is major variation visible with the highest risk and lowest risk areas when the weighting changes from $30-50 \%$. The dramatic difference is $34 \%$ for the highest risk area and $49 \%$ for the lowest risk area. Therefore, the model is highly sensitive to the lineament parameter (Fig. 8). The model is also highly sensitive to the slope factor in the study area. In the first weighting scheme, most of the area falls in the medium risk zone $(81 \%)$, which gradually decreases to $62 \%, 47 \%$, and $33 \%$, respectively, for each step (20\%) of weight increment. There are intense changes for lowest risk and highest risk rockfall areas for different weighting percentages. It was observed that the area of risk increases with the highest risk area to about $20 \%$ of the total area if the weight was changed from $10-30 \%$. If the slope weight changes from $30-50 \%$, the highest rockfall risk area decreases by approximately $20 \%$.

The rockfall model is highly sensitive with regard to the depth of seismic activity in the study area. In the first weighting scheme, most of the area falls in the medium risk zone $(82 \%)$, which gradually decreases to $67 \%, 29 \%$, and $27 \%$, respectively, for every weight increment of $20 \%$. The change of weight depth of seismic activity from 10-30\% weight increases the highest risk area by about $25 \%$ of the total area. Afterwards, a change of 30-50\% weight, decreases the highest rockfall risk area by approximately $37 \%$. Similarly, in the last scheme, $3 \%$ inclination of the quantity of the highest risk zone is visible. However, it proves that potential rockfall occurrence is highly sensitive to the depth of seismic activity, to geology (although considerably less), and to lineament density. 
Table 3 Weights of parameters selected as compared with other literature

\begin{tabular}{lll}
\hline Parameter & $\begin{array}{l}\text { Weight from } \\
\text { sensitivity analysis }\end{array}$ & Weight from other research \\
\hline Lithology & 5 & 4 (Arnous 2011), 6 (Çelik and Gülersoy 2017) \\
Lineament density & 5 & 5 (Arnous 2011) \\
Slope & 4 & 5 (Arnous 2011), 5 (Çelik and Gülersoy 2017) \\
Depth of seismic activity & 4 & 5 (Arnous 2011) \\
Magnitude of seismic activity & 3 & 5 (Arnous 2011) \\
Aspect & 3 & 4 (Arnous 2011), 3 (Çelik and Gülersoy 2017) \\
Rainfall intensity & 2 & 1 (Çelik and Gülersoy 2017) \\
Elevation & 1 & 3 (Arnous 2011), 2 (Çelik and Gülersoy 2017)
\end{tabular}

Through the magnitude of seismic activity, there are gradual changes in the areas of risk involving rockfall with the changes in the weighting of the factor from $10 \%, 30 \%$, $50 \%$, and $70 \%$. The variation is minor for the highest risk zone with the change of the weighting. The percentage of highest risk area is $13 \%, 1 \%, 0.5 \%$ and $0.5 \%$ for changes of $10 \%, 30 \%, 50 \%$, and $70 \%$, respectively. These results indicate that the magnitude is slightly sensitive compared to other factors considered. The percentages for highest risk area are $9 \%, 5 \%, 5 \%$, and $7 \%$ for the weight of elevation parameters $10 \%, 30 \%, 50 \%$, and $70 \%$, respectively. The variation of highest risk zone when the weight increases are $4 \%, 0 \%$, and $2 \%$, respectively. Therefore, the variation is slight for the highest risk zone with a change of the weighting.

It can be observed that the change of the highest risk area is minor when the weighting for the aspect parameter increases from 50-70\%. Although there are changes in the risk areas, they are relatively gradual for different weighting schemes. The highest risk zone is $9 \%, 18 \%, 27 \%$, and $28 \%$ for the aspect parameter weighting of $10 \%, 30 \%, 50 \%$, and $70 \%$, respectively. For the rainfall parameter, there are changes in the risk areas when the weighting of the rainfall parameter changes from 10-30\%. It can be seen that the change in the area is not significant when weighting for rainfall intensity increases from $50-70 \%$. The highest risk zone is $8 \%, 20 \%$, and $25 \%$ for the rainfall intensity weightings of $10 \%, 30 \%$, $50 \%$, and $70 \%$, respectively. This analysis depicts the medium type of rockfall sensitivity to rainfall intensity in the study area.

Based on the sensitivity analysis of the different parameters, the percentage for the highest risk zone for the lithology parameter is great in comparison to elevation, rainfall, and
Fig. 9 a RHZ map of study area, b Percentage of RHZ in study area

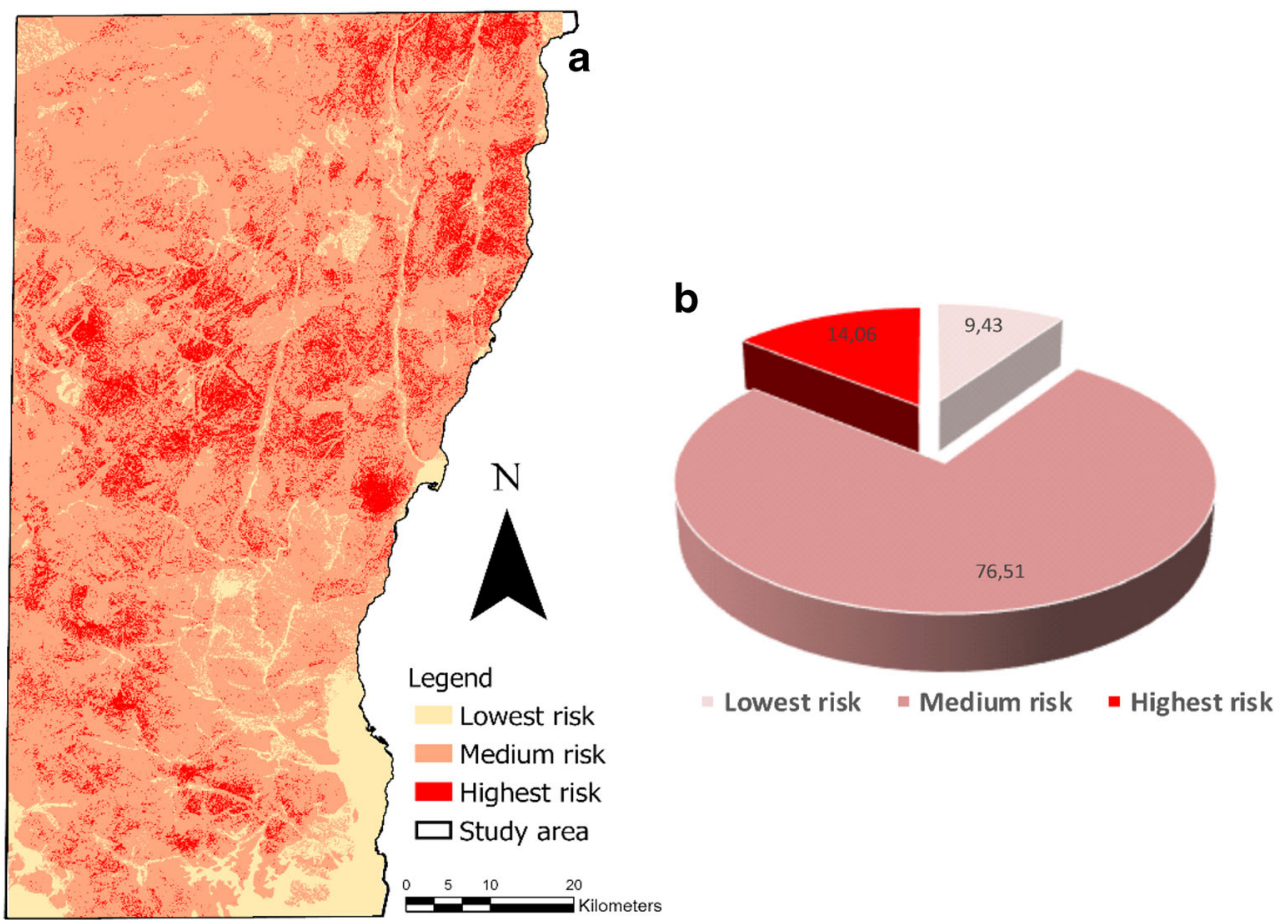



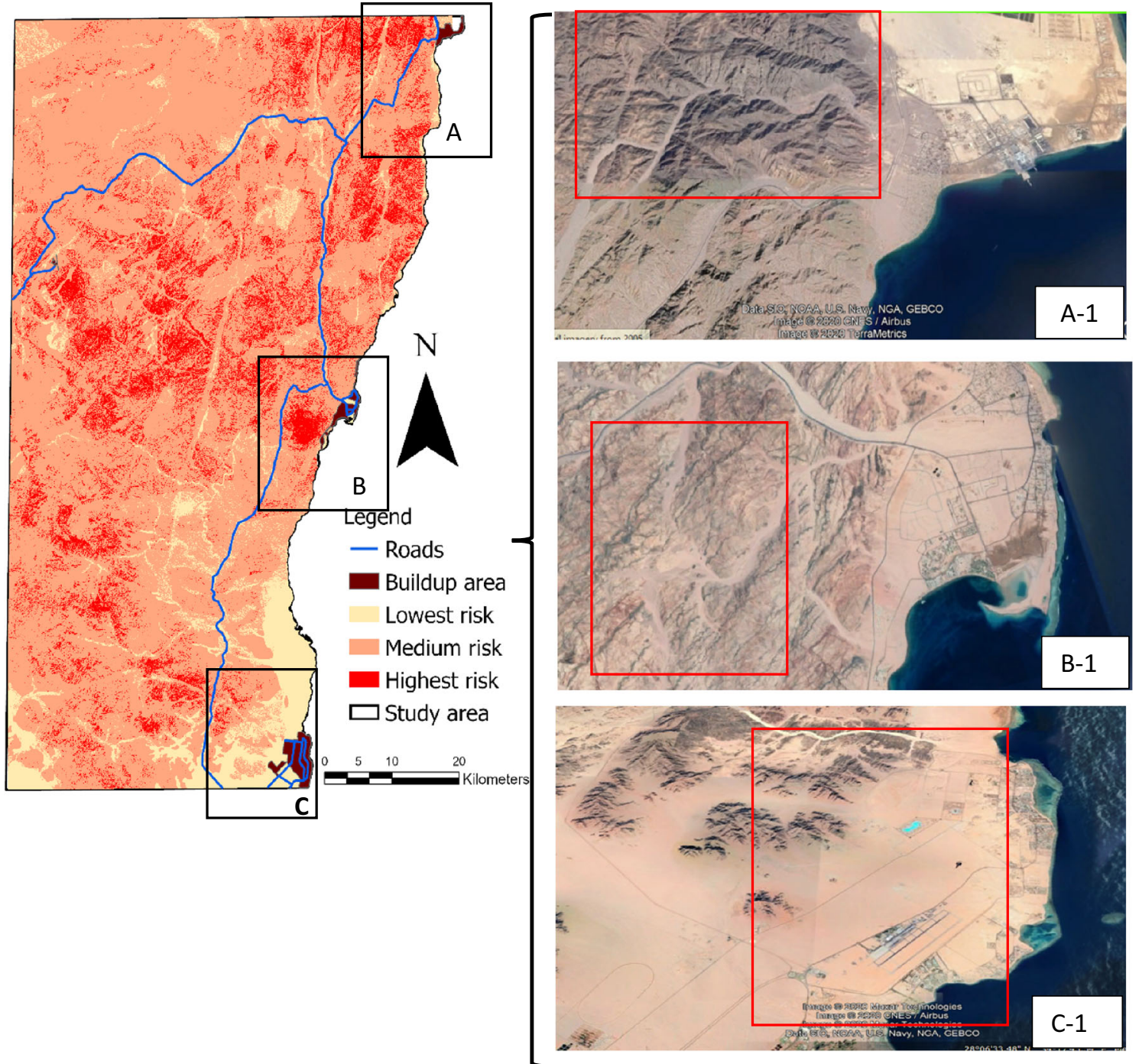

Fig. 10 a, b \& c Selected locations at the study area for comparison of RHZ map and land use; and (A-1, B-1 \& C-1) Google Earth Pro images for selected location in study area

aspect. The effect of changes at risk areas was clearly shown regarding lineament, slope, and depth of seismic activity parameters in comparison with magnitude, elevation, and rainfall. Therefore, the sensitivity of the parameters on potential rockfall events is ordered as Lithology $>$ Structure lineament $>$ Slope $>$ Depth of seismic activity $>$ Magnitude of seismic activity $>$ Aspect $>$ Rainfall intensity $>$ Elevation. Finally, according to their sensitivity characteristics, weights are assigned to the parameters as presented in Table 3 . Furthermore, weights considered in some relevant previous studies are also tabulated.

The values of the final weighted sum layer, after applying the score and weight values, ranged from between 0 and 2100 . In the final step, the RHZ map was created by reclassifying the weighted sum layer into three classes using equal intervals (Fig. 9a). Figure 9b shows the percentage of the three classes in the study area as a pie chart. Most of the area $(76.51 \%)$ is in the medium risk zone. $9.43 \%$ of the total area is classified as low risk zone. The remaining $14.06 \%$ corresponds to the highest risk zone according to the output of the model.

For an assessment of the risk map on the surrounding property and habitants, a main land use layer was overlaid with the RHZ map, containing main land use features such as main roads and developed areas extracted from Google Earth Pro orthophoto for November 2018 (Fig. 10). The study area has a low density of population within its mountainous environment. Nevertheless, this area is considered to be an important spot for tourism because of the nearby diving areas within the Gulf of Aqaba. Figure 10 shows that there are some high-risk zones beside the highway and near the developed areas.

The areas of higher risk are located along the western part of the investigated area, especially at the lower reaches of Dahab basin, the area between Nuweiba and Dahab as well as at the developed area of Nuweiba. While the lower risk areas are concentrated mainly at the alluvial wadi and at the coastal area of the cities of Dahab, Nuweiba, and Sharm El 

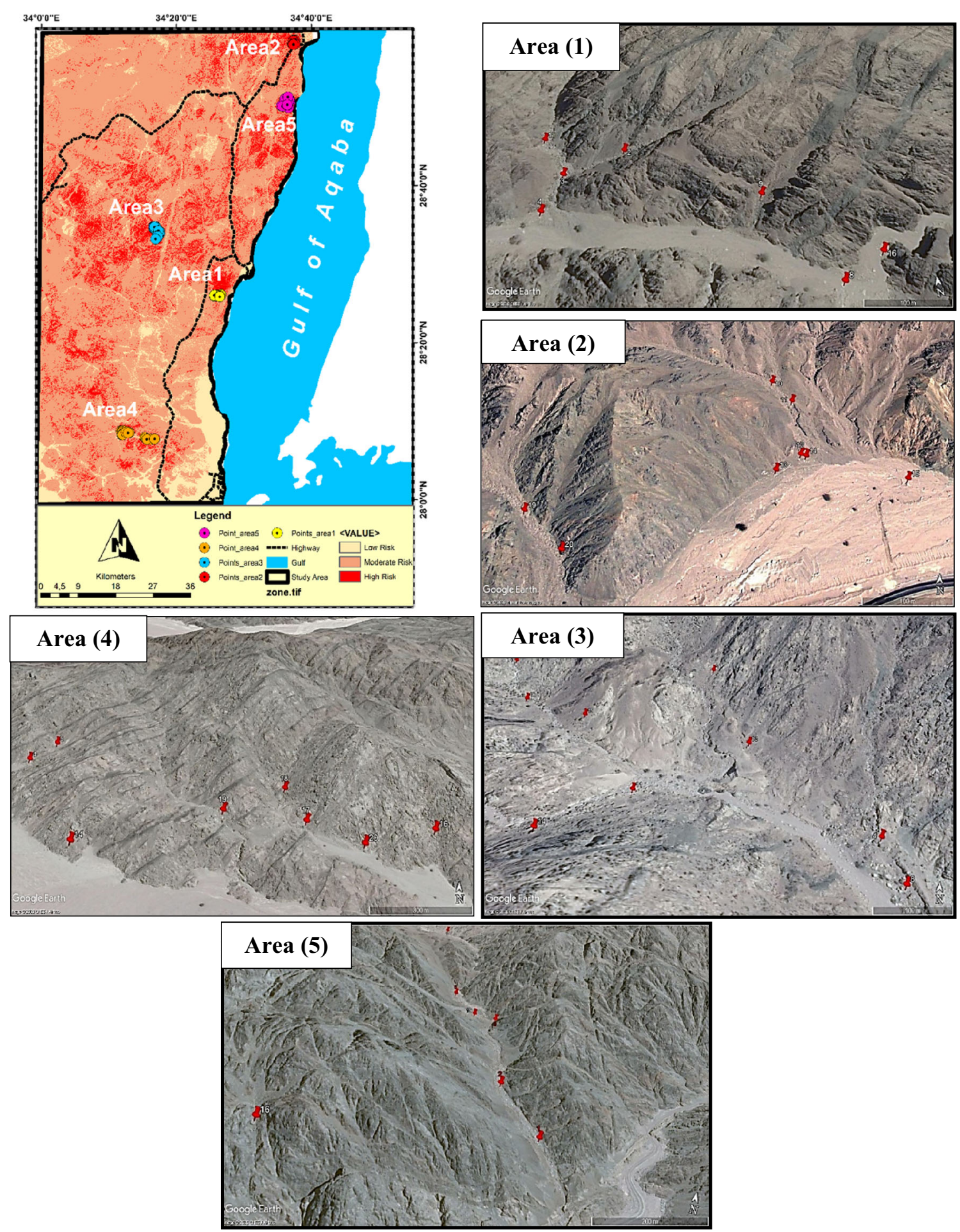

Fig. 11 The selected spot areas showing the observed rockfall bodies

Sheikh. Three selected areas have been investigated further to validate the results of the rockfall model by comparing them with Google Earth Pro orthophotos. These areas were selected because they have different land use and land cover features on the land surface such as roads and settlement.

Figure 10c and c-1 shows that the highest rockfall zone has an undulated surface near the developed area of Sharm El
Sheikh city: high risk areas are found near to the developed area of Dahab and also near the highway between Dahab and Sharm El Sheikh (Fig. 10b and b-1), as well as in the mountainous area located along the southern part of the city of Nuweiba (Fig. 10a and a-1). It can be stated that most of the study area was classified as moderate risk zone. This simple validation confirms that the RHZ model results are reliable but 
Table 4 Validity of RHZ map with the selected spot areas

\begin{tabular}{|c|c|c|c|c|c|c|}
\hline & Risk Area & Area $\left(\mathrm{Km}^{2}\right)$ & Area(\%) & $\begin{array}{l}\text { Rockfall } \\
\text { frequency (RFF) }\end{array}$ & $\begin{array}{l}\text { Rockfall density } \\
\left(\mathrm{RFF} / \mathrm{km}^{2}\right)\end{array}$ & $\begin{array}{l}\text { Confidence } \\
\text { rate }(\%)\end{array}$ \\
\hline \multirow[t]{4}{*}{ Area 1} & Low & $*$ & $*$ & $*$ & $*$ & $*$ \\
\hline & Moderate & 6,81432 & 59,20 & 8 & 1,17 & 40 \\
\hline & High & 4,687744 & 40,80 & 12 & 2,55 & 60 \\
\hline & Total & 11,502064 & 100 & 20 & 3,72 & 100 \\
\hline \multirow[t]{4}{*}{ Area 2} & Low & $*$ & $*$ & $*$ & $*$ & $*$ \\
\hline & Moderate & 4,34128 & 36 & 9 & 2,073 & 45 \\
\hline & High & 7,689184 & 64 & 11 & 1,43 & 55 \\
\hline & Total & 12,030464 & 100 & 20 & 3,503 & 100 \\
\hline \multirow[t]{4}{*}{ Area 3} & Low & 0,137664 & 1,00 & $*$ & $*$ & $*$ \\
\hline & Moderate & 6,406128 & 54,00 & 8 & 1,248 & 40 \\
\hline & High & 5,39928 & 45,00 & 12 & 2,225 & 60 \\
\hline & Total & 11,943072 & 100 & 20 & 3,325 & 100 \\
\hline \multirow[t]{4}{*}{ Area 4} & Low & 1,237104 & 9,719 & $*$ & $*$ & $*$ \\
\hline & Moderate & 8,260608 & 64,89 & 6 & 0,726 & 30 \\
\hline & High & 4,46784 & 25,391 & 14 & 3,314 & 70 \\
\hline & Total & 12,728448 & 100 & 20 & 1,91 & 100 \\
\hline \multirow[t]{4}{*}{ Area 5} & Low & 0,142848 & 1,00 & $*$ & $*$ & $*$ \\
\hline & Moderate & 5,631984 & 54,00 & 8 & 1,42 & 40 \\
\hline & High & 4,683888 & 45,00 & 12 & 2,561 & 60 \\
\hline & Total & 10,45872 & 100 & 20 & 3,83 & 100 \\
\hline
\end{tabular}

(*) No data this result depends on the data related to rockfall triggering factors.

\section{Verification RHZ model}

For checking the reliability of the model, ground truth validation is needed. The required data may be collected by field survey or extracted from aerial photos (Weirich and Blesius 2007). Qualitative validation involves overlaying the independent ground truth data with the model and carrying out a visual inspection. Quantitative validation may be done by deriving indices such as the 'area of susceptibility class occupied by landslide' divided by 'area of susceptibility class', or the histogram divided by the cumulative curve (Chung and Fabbri 2003; Remondo et al. 2003).

The accurate detection of rockfall locations as ground truth data is important for RHZ analysis. A field survey is the best method for detecting rockfall, but field surveys are difficult, time-consuming, and costly - especially in mountainous areas where access is difficult or even impossible. In this study, rockfall sites have been mapped using Google Earth Pro orthophotos and then compared with the RHZ mapping. However, this method can be used only at a regional scale as there is a limitation on the quality of the input data. In addition, the result of this method cannot be used as a substitute for site specific work and professional advice from qualified geologists and geotechnical engineers. However, it can be guidance for a larger scale mapping. The initial focus was on the spot areas of high risk zone as characterized by a high relief and steep slopes in mountainous areas and the steep valley slopes of the main streams traversing the study area. Five areas have been selected for different sites of the study area (Fig. 11). Twenty point locations of rockfall have been extracted from Google Earth Pro orthophotos for each of the five spot areas.

The results confirmed that most of the rockfall points are located either in the moderate or high risk zone in all the selected areas (Table 4). The majority of rockfall points are located in high risk zones which are characterized by high slope, highly dissected with structured lineaments, and with hard rocks as lithological character. Many of the rockfall points have been settled in the moderate hazard zone. The statistical relationship of RHZ and rockfall points revealed that the majority of falling rock materials are sited at the high risk zone with a degree of confidence (55-70\%), while the degree of confidence at the moderate risk zone is between $(30-45 \%)$. The rockfall density is increased at the moderate and high risk zones while rockfall points have not been observed at the low risk zone. The density of rock fall points is raised in the high risk zone at area 1 (near the city of Dahab), at 
area 3 (in the middle part of study area), at area 4 (in the southern part of study area) and at area 5 (in the northern coastal part of the study area).

When the rocks detached from the steep slopes or cliff face, then the falling material moves abruptly with high speed downward to the slope base. The falling materials may be rock blocks or small pieces of rock fragments. The falling blocks can be rolling for a long distance after falling thereby reaching more gently sloped and lower elevation areas. This movement can directly affect the highways and other infrastructure, as well as people. Therefore, this type of movement may start at the source zone which is part of the high risk zone, especially, at the high elevation and high steeply sloped areas.

The falling of rock material can be settled at moderate risk zones because of the gravitational factor, where the moderate zones are located adjacent to the high risk zones. Therefore, the high risk zone areas are represented as the source of falling rock while the moderate risk zones are considered as receptors for fallen rocks because of the natural hazard factors such as earthquakes and runoff. The results confirmed that the moderate risk zone represents a highly covered area in the model results where most of falling blocks are located at the same zone and most of the important highways are passing through the same risk zone.

\section{Conclusion and recommendation}

Rockfall hazards are inevitable and it is almost impossible to fully recover from the damage caused by such events. The occurrence of rockfall hazard and their increasing frequency, not only in Egypt but also all over the world, is a major concern for the population residing in mountainous terrain and poses a serious threat to the economic development of such regions. Many rockfall hazard zones are not suitable to be used for residential purposes. Therefore, to mitigate the risks for residential areas, RHZ model could help to minimize the potential risk by implementing rockfall resilience plans, and to support rehabilitation and disaster reduction.

The main objective of this research work was to develop a user-friendly RHZ model implementation. The time required to run the model depends on the size of the input data and the extent of the area of interest. As the final RHZ map depends entirely on the input data, selected ratings, and scores, therefore ground truthing is of major importance towards getting reliable results. For the study area, validation indicates the reliability of the model implemented. Hence, acquired RHZ can be used for urban planning, engineering works, and protection planning with further investigation.

Eight parameters have been used in the model to prepare a RHZ map based on the rating and weighting of geological, topographical, seismic activity, and rainfall parameters. The map may be used as a basis for spatial prediction of rockfall-prone areas at a regional scale, providing guidance for further and more detailed investigations at larger scale. It represents areas potentially exposed to rockfall and provides the first preliminary information towards land use decisions by governmental administrations. Each parameter has been scored regarding previous studies in soil erosion and rockfall modeling. The sensitivity analysis has shown that the influential weighting parameters on rockfall hazard in the study area are lithology and structure lineament while the elevation and rainfall parameter have lesser influence on the rockfall hazard.

The resulting zonation map of the model showed that $14 \%$ of the total area being studied has high risk for potential RHZ. These high risk areas are concentrated mainly near the highways connecting the main cities and near the developed areas. The $9.5 \%$ areas with low risk potential are mainly located at the coast and at the main outflow stream of the wadi. Although there are no official records of rockfall events for the study area, this work may be used by decision makers having concern about this hazard, especially at this important area of tourism.

The model implemented has the advantage of allowing other parameters affecting rockfall hazard to be added easily. On the other hand, the model results will be less reliable if the user cannot provide data for all of the eight factors as input. To avoid the damaging of nearby developed area and land use in the study area, field investigation is essential towards making a detailed analysis on the actual conditions in the high risk zone. To avoid loss of property and lives by falling rocks in the high and medium risk zone along the roads and the developed areas, mitigation measures such as rock bolts or protective fencing should be considered.

Acknowledgements The authors would like to thank the Department of Geomatics, Faculty of Geomatics, Computer Science and Mathematics, Hochschule für Technik Stuttgart- Germany, the Geological Department at Suez Canal University- Egypt, and the Geographical Institute at the University of Tuebingen- Germany, for providing relevant data and support to complete this study.

Funding This work was supported by the Natural Science Foundation of Chongqing (No. cstc2020jcyj-msxmX0853) and the Joint Medical Research Project of Chongqing Municipal Science and Health Commission (No.2020MSXM094).

Open Access This article is licensed under a Creative Commons Attribution 4.0 International License, which permits use, sharing, adaptation, distribution and reproduction in any medium or format, as long as you give appropriate credit to the original author(s) and the source, provide a link to the Creative Commons licence, and indicate if changes were made. The images or other third party material in this article are included in the article's Creative Commons licence, unless indicated otherwise in a credit line to the material. If material is not included in the article's Creative Commons licence and your intended use is not permitted by statutory regulation or exceeds the permitted use, you will need to obtain permission directly from the copyright holder. To view a copy of this licence, visit http://creativecommons.org/licenses/by/4.0/. 


\section{References}

Al-Mashreki MH, Akhir JBM, Rahim SA, Desa KM, Lihan T, Haider AR (2011) GIS-based sensitivity analysis of multi-criteria weights for land suitability evalua-tion of sorghum crop in the Ibb Governorate, Republic of Yemen. J Basic Appl Sci Res 1(9): 1102-1111

Archer GEB, Saltelli A, Sobol IM (1997) Sensitivity measures, ANOVAlike techniques and the use of bootstrap. J Stat Comput Simul 58(2): 99-120

Arnous MO (2011) Integrated remote sensing and GIS techniques for landslide hazard zonation: a case study Wadi Watier area, South Sinai, Egypt. J Coast Conserv 15(4):477-497. https://doi.org/10. 1007/s11852-010-0137-9

Arnous MO, Green DR (2011) GIS and remote sensing as tools for conducting geo-hazards risk assessment along Gulf of Aqaba coastal zone, Egypt. J Coast Conserv 15(4):457-475. https://doi.org/10. 1007/s11852-010-0136-x

Bauer M, Neumann P (2011) A guide to processing rock-fall hazard from field data. In: Vogt N, Schuppener B, Straub D, Bräu G (eds) 3rd international symposium on veotechnical safty and risk (ISGSR. 2011). Bundesanstalt für Wasserbau, Karlsruhe, pp 149-156

Blais-Stevens A, Behina P, Kremer M, Page A, Kung R, Bonham-Carter G (2012) Landslides susceptibility mapping of the sea to Sky transportation corridor, British Columbia, Canada: comparison of two methods. Bull Eng Geol Environ, Springer, 71(3):447-466. https:// doi.org/10.1007/s10064-012-0421-z

Brideau MA, Stead D, Kinakin D, Fecova K (2005) Influence of tectonic structures on the Hope Slide, British Columbia, Canada. Eng Geol $80: 242-259$

CALTRANS (2014) Geotechnical manual. Department of Transportation (DOT) of California, Sacramento

Çelik MA, Gülersoy AE (2017) Evaluation of rock fall risk in Kilis (Turkey) City by using GIS and remote sensing. Int J Comput Exp Sci Eng (IJCESEN) 3(2):1-4

Christchurch City Council (2013) Technical guideline for rockfall protection structures. Version 2:27 p

Chung CJ, Fabbri AG (2003) Validation of spatial prediction models for landslide hazard mapping. Nat Hazards 30(3):451-472

Contino A, Bova P, Esposito G, Giuffré I, Monteleone S (2017) Historical analysis of rainfall-triggered rockfalls: the case study of the disaster of the ancient hydrothermal Sclafani Spa (Madonie Mts, northern-central Sicily, Italy) in 1851. Nat Hazards Earth Syst Sci 17(12):2229-2243

Crane E (2015) The rising danger of fooding in Egypt. https:/climate. earthjournalism.net/2015/12/07/extreme-rainstorms-sweepthrough-egypt/. Accessed 10 Jan 2017

Crosetto M, Tarantola S, Saltelli A, Agriculture (2000) Sensitivity and uncertainty analysis in spatial modelling based on GIS. Ecosyst Environ 81(1):71-79

Dai FC, Xu C, Yao X, Xu L, Tu XB, Gong QM (2011) Spatial distribution of landslides triggered by the $2008 \mathrm{Ms} 8.0$ Wenchuan earthquake, China. J Asian Earth Sci 40(4):883-895

D'Amato J, Guerin A, Hantz D, Rossetti JP, Jaboyedoff M (2015) Investigating rock fall frequency and failure configurations using terrestrial laser scanner. In: Lollino $\mathrm{G}$ et al (eds) Engineering Geology for Society and Territory - vol 2. Springer, Cham, pp 1919-1924

DeGraff JV, Romesburg HC (1980) Regional landslide - susceptibility assessment for wildland management: a matrix approach, Thresholdsin Geomorphology. George Allen \& Un-win, Boston, pp 401-414

Depountis N, Nikolakopoulos K, Kavoura K, Sabatakakis N (2019) Description of a GIS-based rockfall hazard assessment methodology and its application in mountainous sites. Bull Eng Geol Environ 79: 645-658. https://doi.org/10.1007/s10064-019-01590-3

Dorren L, Seijmonsbergen A (2003) Comparison of three GIS-based models for predict-ing rockfall runout zones at a regional scale. Geomorphology 56:49-64

Duarte RM, Marquínez J (2002) The influence of environmental and lithologic factors on rockfall ata regional scale: an evaluation using GIS. Geomorphology 43(1-2):117-136

Duran Robert L (2016) Characterization and analysis of a large rockfall along the Rio Cha-ma, Archuleta County, Colorado, Geography

EGSMA (1994) Egyptian Geological Survey and Mining Authority. Geologic map of Sinai, Arab Republic of Egypt. Sheet No.1, Scale $1: 250.000$

Egypt today (2019) https://www.egypttoday.com/Article/1/64254/16Accessed 23.07.2020

El Rayes A, Omran A, Geriesh M, Hochschild V (2020) Estimation of hydraulic conductivity in fractured crystalline aquifers using remote sensing and field data analyses: An example from Wadi Nasab area, South Sinai. Egypt J Earth Syst Sci 129:203. https://doi.org/10. 1007/s12040-020-01470-5

Eyal M, Eyal Y, Bartov, Steinitz G (1981) The Tectonic development of the western margin of Gulf of Elat (Aqaba) rift. Tectonophysics 80: $39-66$

Frayssines M, Hantz D (2006) Failure mechanisms and triggering factors in calcareous cliffs of the Supalpine ranges (French Alps). Eng Geol $86: 256-270$

Frey HC, Mokhtari A, Zheng J (2004) Recommended practice regarding selection, application, and interpretation of sensitivity analysis methods applied to food safety risk process models. US Department of Agriculture. http://www.ce.ncsu.edu/risk/ Phase3Final.pdf. Accessed 15 Dec 2019

Garfunkel Z (1981) Internal structure of the Dead Sea leaky transform (rift) in relation to plate kinematics. Tectonophysics 80:81-108

Gelaro R, Mccarty W, Suárez MJ, Todling R, Molod A, Takacs L, Randles CA, Darmenov A, Bosilovich MG, Reichle R, Wargan K, Coy L, Cullather R, Draper C, Akella S, Buchard V, Conaty A, Silva AMD, Gu W, Kim GK, Koster R, Lucchesi R, Merkova D, Nielsen JE, Partyka G, Pawson S, Putman W, Rienecker M, Schubert SD, Sienkiewicz M, Zhao B (2017) The modern-era retrospective analysis for research and applications, version 2 (MERRA-2). J Clim 30(14):5419-5454. https://doi.org/10.1175/jcli-d-16-0758.1

Ghorab MA (1961) Abnormal Strarigraphic Features in Ras Gharib Oil Field. Proceedings of the 3rd Arabian Petroleum Congress, 2, 1-10

Goff J, de Freitas C (2016) Natural hazard in Australia. Cambridge University Press, Milbourn, p 266

Harp E, Jibson R (1996) Landslides triggered by the 1994 Northridge, California, earth-quake. Bull Seismol Soc Am 86(1B):S319- S332

Hoek E, Bray JW (1981) Rock Slope Engineering, 3rd edn. Institute of Mining and Metallurgy, London, 358p

Hungr O, Leroueil S, Picarelli L (2014) The Varnes classification of landslide types, an update. Landslides 11(2):167-194. https://doi. org/10.1007/s10346-013-0436-y

Hussin H, Fauzi NB, Jamaluddin TA, Arifin MH (2017) Rock mass quality effected by lineament using rock mass rating (rmr)-case study from former quarry site. Earth Sci Malays (ESMY) 1(2):1316

Koning DJ, Mansell M (2017) Rockfall susceptibility maps for New Mexico, New Mexico Department of Homeland Security and Emergency Management, $46 \mathrm{p}$

Lambert S, Nicot F (2011) Rockfall Engineering. ISTE. Wiley, London, $435 \mathrm{p}$

Lin X (1999) Flash floods in arid and semi-arid zones. UNESCO, Paris, $65 \mathrm{pp}$

Mair M, Sitzenfrei R, Kleidorfer M, Möderl M, Rauch W (2012) GISbased applications of sensitivity analysis for sewer models. Water 
Sci Technol 65(7):1215-1222. https://doi.org/10.2166/wst.2012. 954

Meisina C, Piccio A, Tocchio A (2001) Some aspects of the landslide susceptibility in the Sorba Valley (western Alps, Italy). In: Proceedings of the International Conference on LandslidesCauses, Impacts and Countermeasures, Davos, Switzerland, 17-21 June 2001; Kuhne M, Einstein HH, Krauter E, Klapperich H, Pottler R (eds). VGE: Essen, pp 547-556

Nassif MS (1997) Stratigraphy and sedimentology of the Eocene rocks at south west Sinai Egypt. Ph.D. Thesis, Suez Canal Univ., Ismailia, Egypt, $197 \mathrm{p}$

Omar NS, Jeber F, Kh, Masor S (2004) GIS/RS for landslides zonation in Pos Slim-Cameron highlands district Peninsula Malaysia. Disaster Prev Manag 13(1):24-32

Omar Kh, El-Amin E, Dahy S, Ebraheem M (2020) Seismic activity and energy release of earthquakes along the Gulf of Aqaba, Egypt. Geotectonics, Springer 53:765-773

Omran A (2013) Application for GIS and Remote sensing for water resource management in Arid Area-Wadi Dahab Basin-South Eastern Sinai-Egypt (Case Study). Dissertation, University of Tübingen, Germany

Polat S, Güney Y (2013) Rock Fall in Bağbaşı Village (Ușak). Uşak Univ J Soc Sci 6(1):207-222

POWER Data Access Viewer (2019) Available at: https://power.larc. nasa.gov/data-access-viewer/. Accessed 10 Oct 2019

Prama M, Omran A, Schröder D, Abouelmagd A (2020) Vulnerability assessment of flash floods in Wadi Dahab Basin, Egypt. Environ Earth Sci 79:114

Remondo J, Gonzalez A, De Teran JRD, Cendrero A, Fabbri A, Chung CJF (2003) Validation of landslide susceptibility maps; Examples and applications from a case study in northern Spain. Nat Hazards 30(3):437-449

Said R (1960) Planktonic foraminifera from the Thebes Formation, Luxor, Egypt. Micropal 6:277-286

Said R (1970) Explanatory notes to accompany the geological map of Egypt. Geol Surv Egypt No 56:123 p
Zhao H, Tian WP, Li J, Ma B (2017) Hazard zoning of trunk highway slope disasters: a case study in northern Shaanxi, China. Eng Geol Environ 77(4):1-10. https://doi.org/10.1007/s10064-017-1178-1

Saltelli A, Chan K, Scott EM (2000) Sensitivity analysis. Willey, New York

Saroglou C (2019) GIS-based rockfall susceptibility zoning in Greece. Geosciences 9:163. https://doi.org/10.3390/geosciences9040163

Sazid M (2019) Analysis of rockfall hazards along NH-15: a case study of Al-Hada road. Int J Geo-Eng 10(1):13. https://doi.org/10.1186/ s40703-019-0097-3

Singh P, Sharma A, Sur U, Rai P (2020) Comparative landslide susceptibility assessment using statistical information value and index of entropy model in Bhanupali-Beri region, Himachal Pradesh, India. Environ Dev Sustain. https://doi.org/10.1007/s10668-020-00811-0

SSRDP-South Sinai Regional Development Programme (2006) Architectural and engineering services for the flood protection of the City of Dahab in South Sinai. The Arab Republic of Egypt (Internal technical Report)

Stoffel M, Ballesteros Cánovas JA, Luckman BH, Casteller A, Villalba R (2019) Tree-ring correlations suggest links between moderate earthquakes and distant rockfalls in the Patagonian Cordillera. Sci Rep 9(1):12112. https://doi.org/10.1038/s41598-019-48530-5

Sur U, Singh P, Meena S (2020) Landslide susceptibility assessment in a lesser Himalayan Road Corridor (India) applying Fuzzy AHP technique and earth-observation data. Geomat Nat Haz Risk 11:21762209. https://doi.org/10.1080/19475705.2020.1836038

Tanyaș H, van Westen J, Persello C, Alvioli M (2019) Rapid prediction of the magnitude scale of landslide events triggered by an earthquake. Landslides 16:661-676. DOI https://doi.org/10.1007/s10346-01901136-4

Weirich F, Blesius L (2007) Comparison of satellite and air photo based landslide susceptibility maps. Geomorphology 87(4):352-364

Publisher's note Springer Nature remains neutral with regard to jurisdictional claims in published maps and institutional affiliations. 